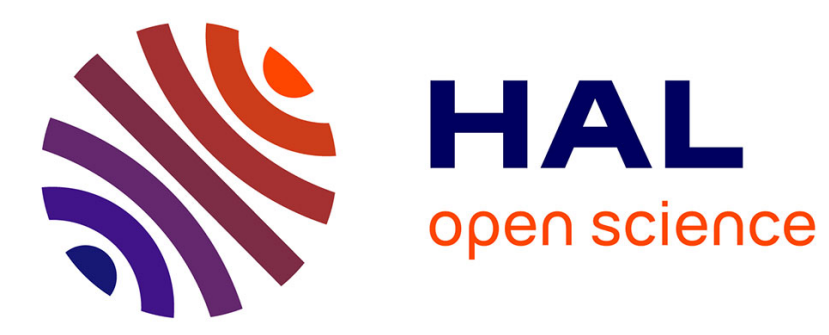

\title{
Electrochemical Noise Measurements with Dummy Cells: Evaluation of a Round-Robin Test Series
}

\author{
François Huet, Stefan Ritter
}

\section{To cite this version:}

François Huet, Stefan Ritter. Electrochemical Noise Measurements with Dummy Cells: Evaluation of a Round-Robin Test Series. Corrosion, 2018, 74 (12), pp.1457-1465. 10.5006/3007 . hal-01950881v2

\section{HAL Id: hal-01950881 \\ https://hal.sorbonne-universite.fr/hal-01950881v2}

Submitted on 20 Dec 2018

HAL is a multi-disciplinary open access archive for the deposit and dissemination of scientific research documents, whether they are published or not. The documents may come from teaching and research institutions in France or abroad, or from public or private research centers.
L'archive ouverte pluridisciplinaire HAL, est destinée au dépôt et à la diffusion de documents scientifiques de niveau recherche, publiés ou non, émanant des établissements d'enseignement et de recherche français ou étrangers, des laboratoires publics ou privés. 


\title{
Electrochemical Noise Measurements with Dummy Cells: \\ Evaluation of a Round-Robin Test Series
}

Submitted for publication: August 8, 2018. Revised and accepted: October 8, 2018. Preprint available online: October 8, 2018, https://doi.org/10.5006/3007.

$$
\text { François Huet }{ }^{\ddagger * *} \text { and Stefan Ritter** }
$$

* Sorbonne Université, CNRS, Laboratoire Interfaces et Systèmes Electrochimiques, F-75005 Paris, France.

** Paul Scherrer Institute (PSI), Nuclear Energy and Safety Research Division, Laboratory for

Nuclear Materials,CH-5232 Villigen PSI, Switzerland.

\begin{abstract}
Round-robin (RR) tests on electrochemical noise (EN) measurements with dummy cells have been performed in the European Cooperative Group on Corrosion Monitoring of Nuclear Materials since 2006. Dummy cells are composed of three resistors of equal value connected in a 'star' arrangement and employed in the conventional three electrode EN measurement setup using a zero-resistance ammeter. The use of dummy cells has the advantage of measuring voltage and current noise signals of reproducible amplitude contrary to corroding systems. The arrangement provides a well-defined source impedance and noise level, thereby allowing the testing of the noise level and sensitivity of the measuring instrument, which is a potentiostat in most cases. Although the resistors used in the dummy cell generate thermal noise of very low level, as low as for passive electrodes, it is not expected that all instruments will be able to measure this noise. From the results of the three RR tests performed between 2014 and 2017 that are presented, it may be concluded that small improvements could be observed compared to the very first RR campaigns, but that still only few commercially available instruments are able to perform fully valid electrochemical noise measurements and that better guidance to the users of such instruments is needed.
\end{abstract}

KEY WORDS: round-robin, electrochemical noise, dummy cell, potentiostat.

¥Corresponding author. Email: francois.huet@sorbonne-universite.fr 


\section{INTRODUCTION}

Electrochemical noise $(\mathrm{EN})$ has been widely used since the first paper by Iverson ${ }^{1}$ to study corrosion processes $^{2-4}$ and since that time EN is claimed to be a promising technique to detect localized corrosion. However, while random signals can be correctly measured with spectrum analyzers since the 1980s, the use of personal computers with data acquisition cards or digital voltmeters since the 1990s often led to improper noise measurements due to aliasing occurring during the analog-to-digital conversion. ${ }^{5}$ This problem is currently ignored in many commercial general-purpose potentiostats and an overview of the EN literature shows that aliasing is almost never addressed in the experimental procedures.

In order to improve the EN measurement procedure and evaluate the limitations of the technique, round-robin (RR) experiments have been organized. The first one was performed by a group based in Germany in 1997, in which potential noise on aluminum without external polarization and current noise on stainless steel under potential control have been measured in three different conditions: passive, pitting, and repassivating/passive ${ }^{6}$. According to the authors, almost all of the participants were able to detect qualitative differences in $\mathrm{EN}$ behavior during the different stages but differences in measured EN signal intensity of two orders of magnitude were obtained as a result of the different apparatus used. Later, the European Cooperative Group on Corrosion Monitoring of Nuclear Materials (ECG-COMON, www.ecg-comon.org) organized RR tests between 2006 and 2008 by using the conventional three-electrode configuration, in which the current noise between two identical working electrodes is measured with a zero resistance ammeter (ZRA). The potential noise of this working electrode pair is, then, measured with respect to a third reference electrode. One of the RR tests was performed on aluminum coupons in three different electrolytes, as in Ref. 6, and the other tests used dummy cells composed of three identical pure resistors to obtain a well-defined source impedance and noise level in contrast to corroding electrodes. ${ }^{7}$ Indeed, these dummy cells produce the thermal noise of 
the resistors, which gives potential and current fluctuations with a constant power spectra density (PSD), 6kTR for the potential noise and 2kT/R for the current noise, where k is Boltzmann's constant, $\mathrm{T}$ is the temperature in $\mathrm{K}$ and $\mathrm{R}$ is the resistance in Ohms. ${ }^{8}$ Resistors of $100 \Omega, 10 \mathrm{k} \Omega$, and $1 \mathrm{M} \Omega$ were used, so that the noise levels were low, in the same range as for passive electrodes, thereby allowing the testing of the base noise level and sensitivity of the measuring instruments. The large scatter in the data measured with the resistive dummy cells in this RR test could only be explained by differences in the quality of the potentiostat used and how it is used, so that few of the results in this work can be regarded as reliable.

In 2014, the ECG-COMON decided to start new noise RR experiments on dummy cells to check if the EN measurement equipment, as well as the users of the equipment have made some "progress." Despite the fact that resistors of higher values (1 M $\Omega$ and $100 \mathrm{M} \Omega$ ) have been used, the thermal noise generated by the resistors has a low level so that it is not expected that it will always be possible to measure this noise, and the objective of the experiment is also to determine the base instrument noise levels. Three RR tests were opened in 2014, 2016, and 2017 to the ECG-COMON members who had access to all results, but they were also opened to non-members who did not have access to all results but received detailed feedback on their own measurements. Manufacturers of potentiostats were also encouraged to participate and provide their own data. The results of all of the trials are summarized in this paper with much attention to problems that were experienced and to the limitations of some measurement equipments used.

\section{EXPERIMENTAL PROCEDURES}

Two dummy cells constructed of three resistors of equal value $(\mathrm{R}=1 \mathrm{M} \Omega$ and $100 \mathrm{M} \Omega)$ and connected in a 'star' arrangement (see Figure 1) were sent to all participants. The dummy cells were assembled by one organization and then sent out to all participants to avoid any major differences. The 
measurement procedure is given in Appendix A. It can be seen that the EN signals must be sampled with at least two sampling frequencies to control the overlap of the PSDs in common frequency ranges and validate the measured data. This validation process has been detailed in a guideline for assessing the EN measurement devices. ${ }^{8}$

The analysis of the tests was performed by a single participant who received data sets composed of several time records, each of them containing potential and current fluctuations sampled at a specific sampling frequency, and was in charge of calculating the two PSDs corresponding to each time record. Table 1 shows the number of participants for each RR test, the number of data sets provided, the number of corresponding time records, and the number of PSDs calculated. The PSD was calculated with a Matlab ${ }^{\dagger}$ script using the algorithm shown in Appendix B and with detrend and pwelch routines. The Fast Fourier Transform (FFT) was preferred over the Maximum Entropy Method (MEM) that sometimes gives PSDs with an artificial low-frequency plateau. ${ }^{9}$ To improve the accuracy of the PSDs calculated with the FFT technique, each time record was divided in $\mathrm{N}$ sections of 512 data points, $\mathrm{N}$ varying from 8 to 350 according to the length of the time record, and an average PSD was calculated.

Commercial, mostly general-purpose, potentiostats $^{\dagger}$, from ten different manufacturers (ACM Instruments (A, Gill AC), Bio-Logic (B, SP-150, SP-200, SP-300, VMP3, software EC-Lab), CH Instruments (C, CHI660E, CHI760E), Gamry (G, PCI4/300, Ref600, Ref600+, Interface1000, software EN120, ESA400, ESA410), Ivium Technologies (I, CompactStat, Vertex), IPS Elektroniklabor GmbH \& Co. KG (J, HRU/ZRA-FG-B, PGU-10V-1A), Metrohm (M, Autolab PGSTAT), Origalys (O, OGS100), Princeton Applied Research (P, PARSTAT, software VersaSTAT), Solartron (S, 1287, Modulab, software Corrware, ECS)) and one custom-built EN system (U) were used in 33 organizations, including 8 manufacturers who sent 17 data sets.

\footnotetext{
$\dagger$ All instruments/manufacturers and software mentioned here are trade names.
} 


\section{RESULTS AND DISCUSSION}

Figure 2A shows the time records of the potential noise sampled at various frequencies for the 1 $\mathrm{M} \Omega$ dummy cells in RR-2016. Extremely large variations in amplitude can be observed, some records being in the $\mu \mathrm{V}$ range, others in the $\mathrm{mV}$ range. It is impossible to quantitatively compare the results in the time domain since the amplitude of the noise, and therefore its standard deviation, depends on the sampling frequency $\mathrm{f}_{\mathrm{s}}$ used, as shown in Figure 2B. As long as the sampling frequency decreases, the peak-to-peak amplitude of the noise diminishes because of the presence of the anti-aliasing analog lowpass filter that must necessarily be used before the analog-to-digital conversion. When $\mathrm{f}_{\mathrm{s}}$ decreases, the filter removes the frequencies above $\mathrm{f}_{\mathrm{s}} / 2$ and the amplitude of the signal is reduced.

It is indeed important to note that, according to Shannon's theorem, all frequencies above the Nyquist frequency, $\mathrm{f}_{\mathrm{s}} / 2$, are aliased to frequencies lower than $\mathrm{f}_{\mathrm{s}} / 2$. As a consequence, in the absence of anti-aliasing filter, all frequencies lower than $\mathrm{f}_{\mathrm{s}} / 2$ are corrupted by aliasing of frequencies higher than $\mathrm{f}_{\mathrm{s}} / 2 .^{5}$ This is illustrated in Figure 3 for the measurement of a white noise (PSD independent of frequency) supplied by a signal generator in the frequency range from DC to $1 \mathrm{kHz}$ and sampled at $\mathrm{f}_{\mathrm{s}}=$ $100 \mathrm{~Hz}$ in the presence (blue curves) or in the absence (red curves) of anti-aliasing filter. The amplitude of the time record is more than three times larger in the absence of the filter, which is confirmed in the frequency domain in which the aliasing of the frequencies between $50 \mathrm{~Hz}$ and $1 \mathrm{kHz}$ increases the amplitude of the PSD in the absence of the filter. The efficiency of the filter is shown by the steep decrease of the PSD (blue curve) at frequencies above the cut-off frequency of $33 \mathrm{~Hz}$. In other words, the absence of such PSD decrease at frequencies close to $f_{s} / 2$ is a clear indication that no anti-aliasing filter was used so that the measurement was corrupted by aliasing and must be disregarded. There is no way to "reconstruct" correct PSDs once aliasing occurred, even using digital filtering. Note that efficient filters are necessary to completely eliminate the $50 \mathrm{~Hz}$ (or $60 \mathrm{~Hz}$ ) and harmonics that are often present in the noise measurements. 
The analysis of the measured signals can only be performed in the frequency domain by comparing their PSDs. It is impossible to plot all PSDs calculated (986) so that only the summary graphs of RR-2017 (77 PSDs in each sub-graph), which are very similar to those of RR-2014 and RR2016, are presented in Figure 4. The PSDs calculated from all time records sent by a given participant are plotted in the same color. For both $1 \mathrm{M} \Omega$ and $100 \mathrm{M} \Omega$ dummy cells, an extremely large scatter in the amplitude of the PSDs is exhibited, roughly more than eight decades above the thermal noise level, that is, more than four decades in Volt or Ampere! However, some curves correspond to the level of the thermal noise, $6 \mathrm{kTR}$ and $2 \mathrm{kT} / \mathrm{R}$, especially for the $100 \mathrm{M} \Omega$ dummy cells while others are only slightly higher, indicating that the EN measured represents the noise level of instruments that are optimally used. Some curves are below this level, which is the minimum of noise that can be measured; this can be explained at high frequency by a filtering of the signals due to the presence of parasitic capacitances between the tracks of the circuit board of the dummy cells or inside the measuring equipment. Mistakes in the experiment or a unit conversion issue are certainly at the origin of the lowest current PSDs in Figure 4B.

The large scatter in the PSD amplitudes can be explained in great part by the absence of (proper) anti-aliasing filters. Indeed, Figure 4 exhibits PSDs that do not overlap in common frequency ranges (see e.g. the PSDs in turquoise and peach colors on the top of Figure 4A). This is better illustrated in Figure 5, which shows PSDs of potential noise measured on $1 \mathrm{M} \Omega$ dummy cells with various instruments in RR-2014. Considering the PSDs of same color, it can be seen that the PSD level increases when the sampling frequency decreases, thereby giving non-overlapping PSDs. Once again, this is explained by aliasing of non-eliminated high frequencies to low frequencies during the analogto-digital conversion due to the absence of filters in these instruments.

It is interesting now to analyze the experiments carried out with a commercial potentiostat equipped with anti-aliasing filters. Figure 6 shows the potential and current PSDs for the $1 \mathrm{M} \Omega$ and 100 
$\mathrm{M} \Omega$ dummy cells in the same scales as in Figure 4. It can be seen that, apart a few exceptions, the overlapping of the PSDs of the signals measured at various sampling frequencies by a given participant is excellent, each PSD exhibiting a sharp decrease at frequencies slightly lower than half the sampling frequency, indicating the presence of an anti-aliasing filter. It can also be noted that a few participants are able to measure the potential thermal noise generated by the $100 \mathrm{M} \Omega$ dummy cell in two frequency decades with this equipment. Compared to Figure 4, the PSDs of the potential fluctuations in Figure 6 are closer to the level of the thermal noise, $6 \mathrm{kTR}$, with the exception of two data sets with unexpected extremely high level due to mistakes in the measurement process. This is also true for the PSDs of the current fluctuations, with a larger scatter in the PSD amplitude than for the potential fluctuations.

It must be realized that it is more difficult to measure current noise than potential noise since two parameters must be fixed adequately, the value of the current-measuring resistor $\mathrm{R}_{\mathrm{m}}$ and the gain of the differential amplifier across the resistor. This is illustrated in Figure 7 exhibiting the results of experiments carried out on a $1 \mathrm{M} \Omega$ dummy cell by a single participant with equipment G. Different PSD levels of the current noise have been obtained according to the current-measuring resistor used. It can be demonstrated that the PSD of the measured current noise can be written as: ${ }^{10-11}$

$$
\Psi_{\mathrm{I}_{\text {meas }}}=\frac{\Psi_{\mathrm{e}_{\mathrm{n}, \mathrm{I}}}}{\mathrm{R}_{\mathrm{m}}^{2}}+\frac{1}{1+4 \pi^{2} \mathrm{R}_{\mathrm{m}}^{2} \mathrm{C}^{2} \mathrm{f}^{2}}\left[4 \mathrm{kT} \frac{1}{\mathrm{R}_{\mathrm{m}}}+\frac{\Psi_{\mathrm{e}_{\mathrm{n}}}}{4 \mathrm{R}^{2}}+2 \mathrm{kT} \frac{1}{\mathrm{R}}\right]
$$

where $\Psi_{\mathrm{e}_{\mathrm{n}, \mathrm{I}}}$ is the PSD of the voltage noise of the differential amplifier, $\Psi_{\mathrm{e}_{\mathrm{n}}}$ is the PSD of the voltage noise of the operational amplifier controlling the potential in the potentiostat, and $\mathrm{C}$ is a capacitor in parallel with the resistor $R_{m}$. For the lowest values of $R_{m}(20$ and $200 \mathrm{k} \Omega$ ) the main source of noise corresponds to the first term in the right-hand side of Equation (1), especially at low frequency, since the PSD is inversely proportional to $\mathrm{R}_{\mathrm{m}}^{2}$. For $\mathrm{R}_{\mathrm{m}}$ ranging between $2 \mathrm{M} \Omega$ and $200 \mathrm{M} \Omega, \Psi_{\mathrm{I}_{\text {meas }}}$ does not depend on $\mathrm{Rm}_{\mathrm{m}}$ below $5 \mathrm{~Hz}$ so that the low-frequency part of the spectrum can be attributed to the 
instrumentation noise, $\Psi_{\mathrm{e}_{\mathrm{n}}} / 4 \mathrm{R}^{2}$. For $\mathrm{R}_{\mathrm{m}}=2 \mathrm{M} \Omega$, the high frequency plateau is given by the sum of the thermal noises of the resistors $R_{m}$ and $R$. For higher values of $R_{m}$, which must be used to measure the thermal noise $2 \mathrm{kT} / \mathrm{R}$ of the dummy cell, the capacitance $\mathrm{C}$ (close to $150 \mathrm{pF}$ for high-frequency measurements) in parallel with $\mathrm{R}_{\mathrm{m}}$ plays a role and explains the filtering of the current signal at a cutoff frequency of $1 /\left(2 \pi R_{m} C\right)$. This frequency decreases when $R_{m}$ increases, which explains the shift on the left of the high frequency part of the PSD. In practice, it is important to adapt the value of $\mathrm{R}_{\mathrm{m}}$ according to the impedance of the electrochemical system under study and to select the highest possible gain of the current amplifier without overload.

Owing to the participation of manufacturers to the RR tests, it was possible to compare the data they sent to those provided by different users of their equipment. Figure 8 compares the results measured on both $1 \mathrm{M} \Omega$ and $100 \mathrm{M} \Omega$ with different equipment from the same manufacturer (B) in the same scales as in Figures 4 and 6. Data sent by the manufacturer give rather good overlap of the PSDs (in black), indicating the presence of anti-aliasing filters in the equipment. In contrast, users of the same equipment provided data showing no PSD overlap (orange and red curves) or PSDs unexpectedly low-pass filtered at about $5 \mathrm{~Hz}$ (blue curves). Therefore, despite the presence of anti-aliasing filters in the equipment, data of poor quality are commonly obtained by those who are not sufficiently trained on how to use the measuring software, in particular to fix the cut-off frequency of the filter for a given sampling frequency. This is a clear indication that guidelines have to be written by the manufacturers to better support the users in adjusting the correct settings (filter, gain, etc.) and thereby improving the quality of their EN measurements. An alternative to avoid wrong instrument settings could also be for the manufacturers to provide "beginner" and "professional" measurement modes, the former with predefining all-purpose settings, the latter letting the user adjust the settings manually.

Another way of low-pass filtering is performed by some equipment that integrate the analog signal over a given time $\theta$, then give digital data at a sampling rate $f_{s}=1 / \theta$. This integration procedure, 
often used for noise reduction purposes, acts indeed as a low-pass filter since fast signal variations are eliminated. However, the transfer function of the filter shows lobes at the sampling frequency $1 / \theta$ and harmonics (see Figure 1 in Ref. 10 ), and the filter attenuation $(2 / \pi=0.637$ ) at half the sampling frequency is low, as is the roll-off slope at the lobe tops (20 dB per frequency decade), indicating that aliasing may occur. Figure 9 shows the PSDs of the potential and current noise measured on dummy cells of $100 \mathrm{M} \Omega$ by different participants using such an equipment (S). When the integration procedure was not used properly, non-overlapping PSDs (turquoise, red, and brown curves) were obtained; otherwise the overlap of the PSDs is acceptable (magenta curves), the level of the potential PSDs corresponding exactly to that of the thermal noise of the dummy cell. However, the PSDs show spikes at frequencies close to $5 \mathrm{~Hz}$ and $10 \mathrm{~Hz}$ that come from aliasing of $50 \mathrm{~Hz}$ and harmonics.

\section{CONCLUSIONS}

New EN round-robin tests on dummy cells have been performed during the last three years by the ECG-COMON, both to evaluate the ability of commercial, mostly general-purpose potentiostats to carry out EN measurements and to determine the instrument noise level. A total of 73 data sets were received from 33 laboratories, including eight manufacturers of the tested equipments. An extremely large scatter in the PSDs, especially those of the current noise, were observed, indicating that very few commercial instruments are able to perform valid noise measurements. The main reason is the absence or wrong settings of anti-aliasing analog low-pass filters that leads to a higher noise level and nonoverlapping of PSDs corresponding to data sampled at different frequencies because of aliasing of high frequencies to low frequencies during the analog-to-digital conversion. Even with instruments equipped with proper filters, data provided by standard users are often questionable due to the difficulty of setting the data acquisition parameters correctly. From the current RR exercise, it is clear that better measuring software are needed, together with tutorials written by the manufacturers for training users 
how to measure the noise of dummy cells and obtain reproducible results, which is not possible with corroding systems. Training users in dedicated courses could also improve the quality of EN measurements. ${ }^{11}$

\section{ACKNOWLEDGEMENTS}

The excellent cooperation with the following participants who sent data for at least one of the three RR tests is gratefully acknowledged (in alphabetical order): Julia Agullo and Benoit Gwinner (CEA-Saclay, France), Toon Baars (Ivium, Netherlands), Mirdash Bakalli (Sika Technology AG, Switzerland), Asuncion Bautista (Univ. Carlos III of Madrid, Spain), Walter-John Chitty (IRSN, France), Jennifer Collier and Jean-Philippe Gravel (Canmet Materials, Canada), Michele Curioni (Univ. of Manchester, UK), Laurent Diguet (Solvay, Belgium), Laetitia Franz and Maxime Valay (Origalys, France), Zdenek Fulin and Jan Vit (UJV Řez, Czech Republic), Peixin He (CH Instruments, USA), Matthias Herbst (AREVA NP, Germany), Arnulf Hoertnagl (Institut für Werkstoffsystemtechnik Thurgau, Switzerland), Tony Horner and Tamara Chapman (Rolls-Royce, UK), Yang Hou (Curtin Univ., Australia), Zsolt Kerner (MTA-EK, Hungary), Xavier Ledoux (CETIMMulhouse, France), Jan Macak (Institute of Chemical Technology, Czech Republic), Nicolas Mary and José Bolivar Vina (INSA-Lyon, France), Dominik Moosbauer (Gamry, USA), Paul Nevitt and Jordan Knapp (National Nuclear Laboratory Limited, UK), Kieu Ngo (Sorbonne Université, France), Johan Öijerholm (Studsvik Nuclear AB, Sweden), Mohammed Reffass and Nicolas Murer (Bio-Logic, France), José M. Sánchez-Amaya (Cadiz Univ., Spain), Peter Schrems (IPS Elektroniklabor GmbH \& Co. KG, Germany), Leah Sheridan (AMETEK Solartron and PAR, USA), Konsta Sipilä (VTT Technical Research Centre, Finland), John Vajo (HRL Laboratories, LLC, USA), Bojan Zajec (ZAG, Slovenia), Wenzhong Zhang (Amec Foster Wheeler, UK). Additional thanks also go to all other members of the ECG-COMON for their support.

\section{REFERENCES}

1. W.P. Iverson, J. Electrochem. Soc. 115, 6 (1968): p. 617-618.

2. C. Gabrielli, F. Huet, M. Keddam, R. Oltra, Corrosion 46, 4 (1990): p. 266-278.

3. R.A. Cottis, Corrosion 57, 3 (2001): p. 265-285. 
4. F. Huet, "Electrochemical noise technique," in: Analytical Methods in Corrosion Science and Engineering, eds P. Marcus, F. Mansfeld, Vol. 22, CRC Press, Taylor \& Francis Group, (Boca Raton, FL, USA, 2006), p. 507-570.

5. I.N. Bastos, F. Huet, R.P. Nogueira, P. Rousseau, J. Electrochem. Soc. 147, 2 (2000): p. 671-677.

6. J. Goellner, A. Burkert, A. Heyn, J. Hickling, Corrosion 55, 5 (1999): p. 476-492.

7. R.-W. Bosch, R. A. Cottis, K. Csecs, T. Dorsch, L. Dunbar, A. Heyn, F. Huet, O. Hyökyvirta, Z. Kerner, A. Kobzova, J. Macak, R. Novotny, J. Öijerholm, J. Piippo, R. Richner, S. Ritter, J.-M. Sánchez-Amaya, A. Somogyi, S. Väisänen, W. Zhang, Electrochim. Acta 120 (2014): p. 379- 389.

8. S. Ritter, F. Huet, R.A. Cottis, Mater. Corros. 63, 4 (2012): p. 297-302.

9. U. Bertocci, J. Frydman, C. Gabrielli, F. Huet, M. Keddam, J. Electrochem. Soc. 145, 8 (1998): p. 2780-2786.

10. U. Bertocci, F. Huet, J. Electrochem. Soc. 144, 8 (1997): p. 2786-2793.

11. F. Huet, K. Ngo, "Electrochemical Noise - Guidance for Improving Measurements and Data Analysis”, CORROSION 2018, paper no. 11042 (Houston, TX: NACE, 2018). 


\section{APPENDIX A: Measurement procedure of the noise RR test with dummy cells}

1) Connect the dummy cell

2) Warm up the system $(t>15 \mathrm{~min})$

3) Electrochemical noise measurements (with the $1 \mathrm{M} \Omega$ dummy cell):

a) EN measurement with the highest possible sampling rate; duration of the measurement depends on the sampling rate: at least 16384 samples (e.g., at $100 \mathrm{~Hz}$ sampling rate $\rightarrow 170 \mathrm{~s}$ measurement time is sufficient)

b) EN measurement for (at least) $1 \mathrm{~h} 10 \mathrm{~min}$ with a sampling rate of $1 \mathrm{~Hz}$ (or as close as possible) to acquire (at least) 4096 samples

c) EN measurement with a sampling rate between the other two; duration of the measurement depends on the sampling rate: at least 16384 samples (e.g., at $10 \mathrm{~Hz}$ sampling rate $\rightarrow 28 \mathrm{~min}$ measurement time is sufficient)

4) Save the EN data obtained in three ASCII files with the columns separated by tabulators (column 1 $=$ time $[\mathrm{s}]$, column $2=$ potential $[\mathrm{V}]$, column $3=$ current $[\mathrm{A}])$, without header and named as follows: “Organisation-RR12-ResistorValue-a.txt”, “Organisation-RR12-ResistorValue-b.txt”, etc. Please make sure that you report the EN data with a dot (.) as decimal sign and that you entered the EN data in Volt and Ampere!

5) Repeat points 3 and 4 above with the $100 \mathrm{M} \Omega$ dummy cell

6) Send the files and a description of the measurement device (manufacturer, type, software, year of purchase, range settings, and filter properties (order and cut-off frequency)) by e-mail no later than May 31 to francois.huet@upmc.fr 


\section{APPENDIX B: Algorithm for PSD calculation with FFT}

- divide the time record in $\mathrm{N}$ sections of $\mathrm{M}=512$ data points

with $\mathrm{N}=\operatorname{int}($ number of data in the file / 512)

- loop $\mathrm{N}$ times

\{

acquisition of $\mathrm{M}$ data points of $\mathrm{x}(\mathrm{t})$

linear detrending

remove the mean value of $\mathrm{x}$ (not informative since it corresponds to frequency 0 )

multiply the result by the Hann window

FFT

PSD calculation: $\quad \Psi_{\mathrm{X}}(\mathrm{m} \Delta \mathrm{f})=\frac{2}{\mathrm{~T}}\left|\mathrm{X}_{\mathrm{T}}(\mathrm{m} \Delta \mathrm{f})\right|^{2}=\frac{2}{\mathrm{M}} \Delta \mathrm{t}\left|\sum_{\mathrm{n}=0}^{\mathrm{M}-1} \mathrm{x}(\mathrm{n} \Delta \mathrm{t}) \mathrm{e}^{-2 \mathrm{i} \pi \mathrm{mn} / \mathrm{M}}\right|^{2}$ \}

- average the N PSDs

- multiply the result by $8 / 3$ since Hann window was used. 


\section{LIST OF CAPTIONS}

TABLE 1. Number of participants and volume of data examined in the RR tests

FIGURE 1. (A) $1 M \Omega$ dummy cell and (B) schematic of the 'star' arrangement.

FIGURE 2. Potential time records measured with the $1 \mathrm{M} \Omega$ dummy cells: (A) all records (102) sampled in RR-2016; (B) potential records sampled at various frequencies $f_{s}$ in RR-2014 with instrument $U$.

FIGURE 3. (A) Time records of a white noise of $1.1 \mathrm{~V}$ peak-to-peak amplitude in the frequency range of DC to $1 \mathrm{kHz}$, sampled at frequency $f_{s}=100 \mathrm{~Hz}$ with and without anti-aliasing filtering;

(B) corresponding PSDs (all measured with instrument $U$ ).

FIGURE 4. PSDs of potential $(A, C)$ and current $(B, D)$ fluctuations measured on dummy cells of $1 M \Omega(A, B)$ and $100 M \Omega(C, D)(R R-2017)$.

FIGURE 5. PSDs of potential fluctuations measured on dummy cells of $1 \mathrm{M} \Omega$ with three commercial equipments $O$ (black), P (blue), S (red) in RR-2014.

FIGURE 6. PSDs of potential $(A, C)$ and current $(B, D)$ fluctuations measured on dummy cells of $1 M \Omega(A, B)$ and $100 M \Omega(C, D)$ with instrument $G(R R-2017)$.

FIGURE 7. PSDs of current fluctuations measured on a dummy cell of $1 \mathrm{M} \Omega$ with equipment $G$ as a function of the I/E range used.

FIGURE 8. PSDs of potential $(A, C)$ and current $(B, D)$ fluctuations measured on dummy cells of $1 M \Omega(A, B)$ and $100 M \Omega(D)$ with equipment $B(R R-2016)$.

FIGURE 9. PSDs of potential (A) and current (B) fluctuations measured on dummy cells of $100 \mathrm{M} \Omega$ with commercial equipment S (RR-2016 and RR-2017). 
TABLE 1

Number of participants and volume of data examined in the RR tests

\begin{tabular}{lcccc}
\hline & $\begin{array}{c}\text { total number of } \\
\text { participants }\end{array}$ & number of data & number of & number of \\
& sets received & data records & PSDs \\
& (manufacturers) & & received & calculated \\
\hline RR - 2014 & $19(7)$ & 22 & 138 & 276 \\
\hline RR - 2016 & $19(6)$ & 27 & 201 & 402 \\
\hline RR - 2017 & $19(3)$ & 24 & 154 & 308 \\
\hline
\end{tabular}


(A)

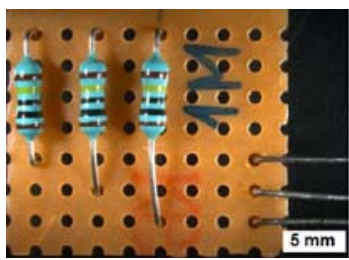

(B)

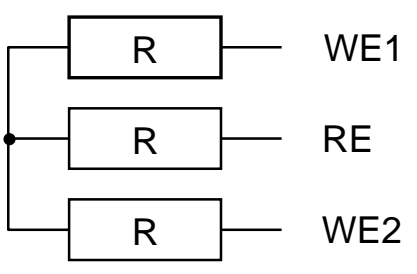

FIGURE 1. (A) $1 \mathrm{M} \Omega$ dummy cell and (B) schematic of the 'star' arrangement.
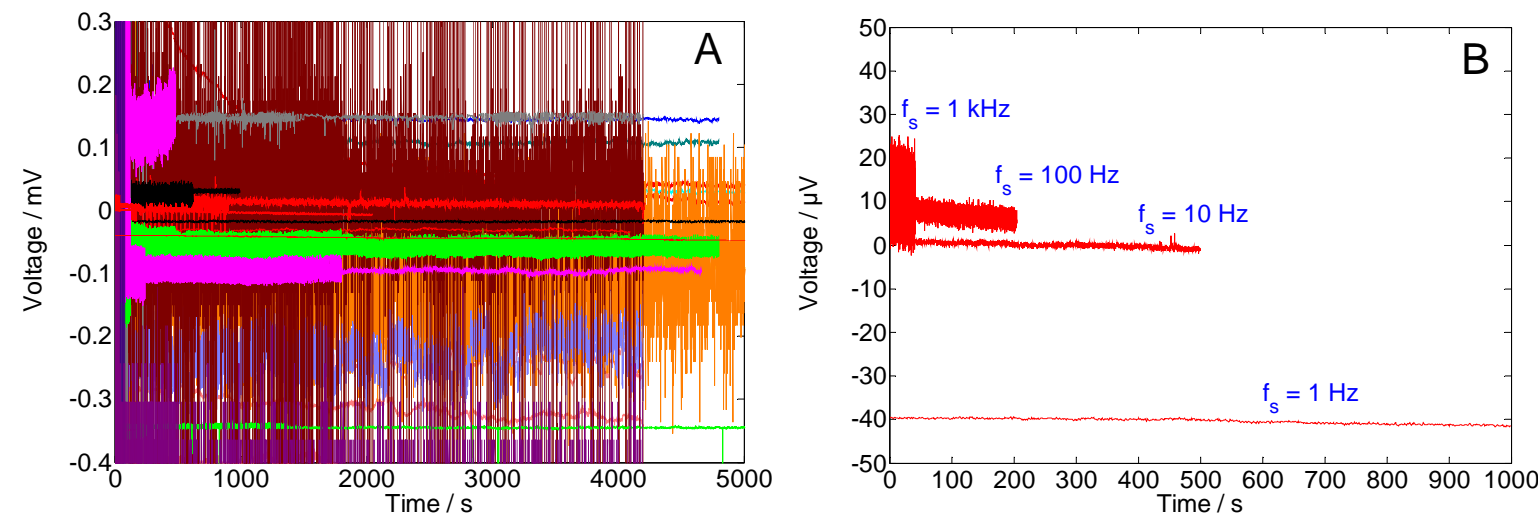

FIGURE 2. Potential time records measured with the $1 \mathrm{M} \Omega$ dummy cells: (A) all records (102) sampled in RR-2016; (B) potential records sampled at various frequencies $f_{s}$ in RR-2014 with instrument $U$. 

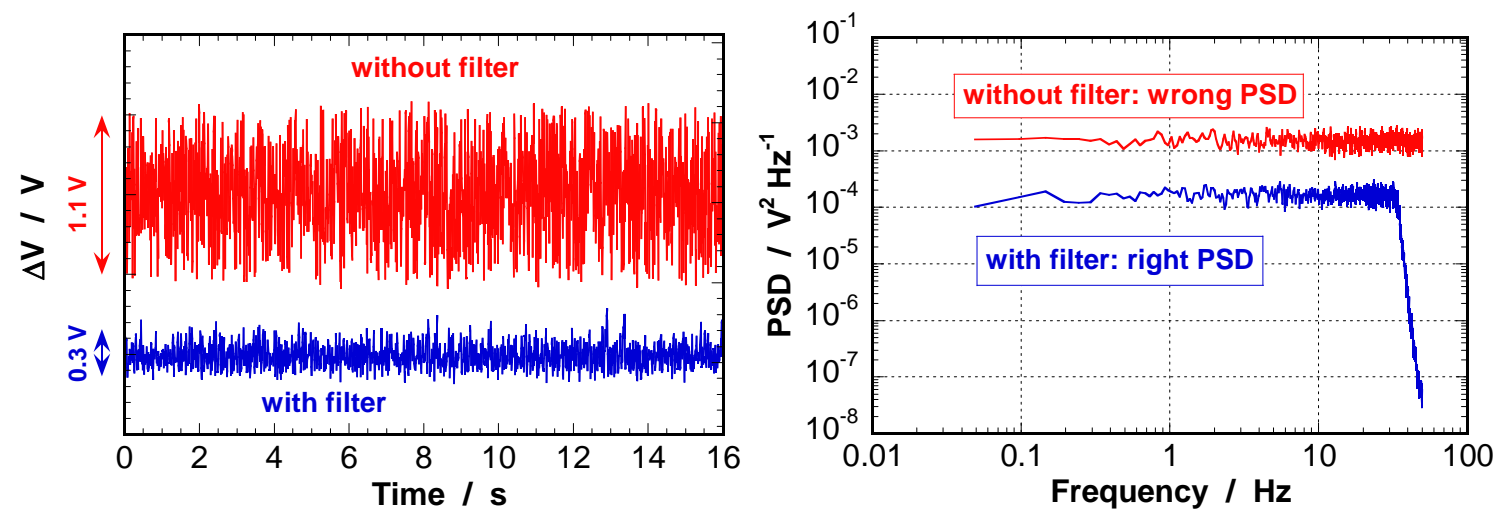

FIGURE 3. (A) Time records of a white noise of $1.1 \mathrm{~V}$ peak-to-peak amplitude in the frequency range of DC to $1 \mathrm{kHz}$, sampled at frequency $f_{\mathrm{s}}=100 \mathrm{~Hz}$ with and without anti-aliasing filtering;

(B) corresponding PSDs (all measured with instrument $U$ ). 

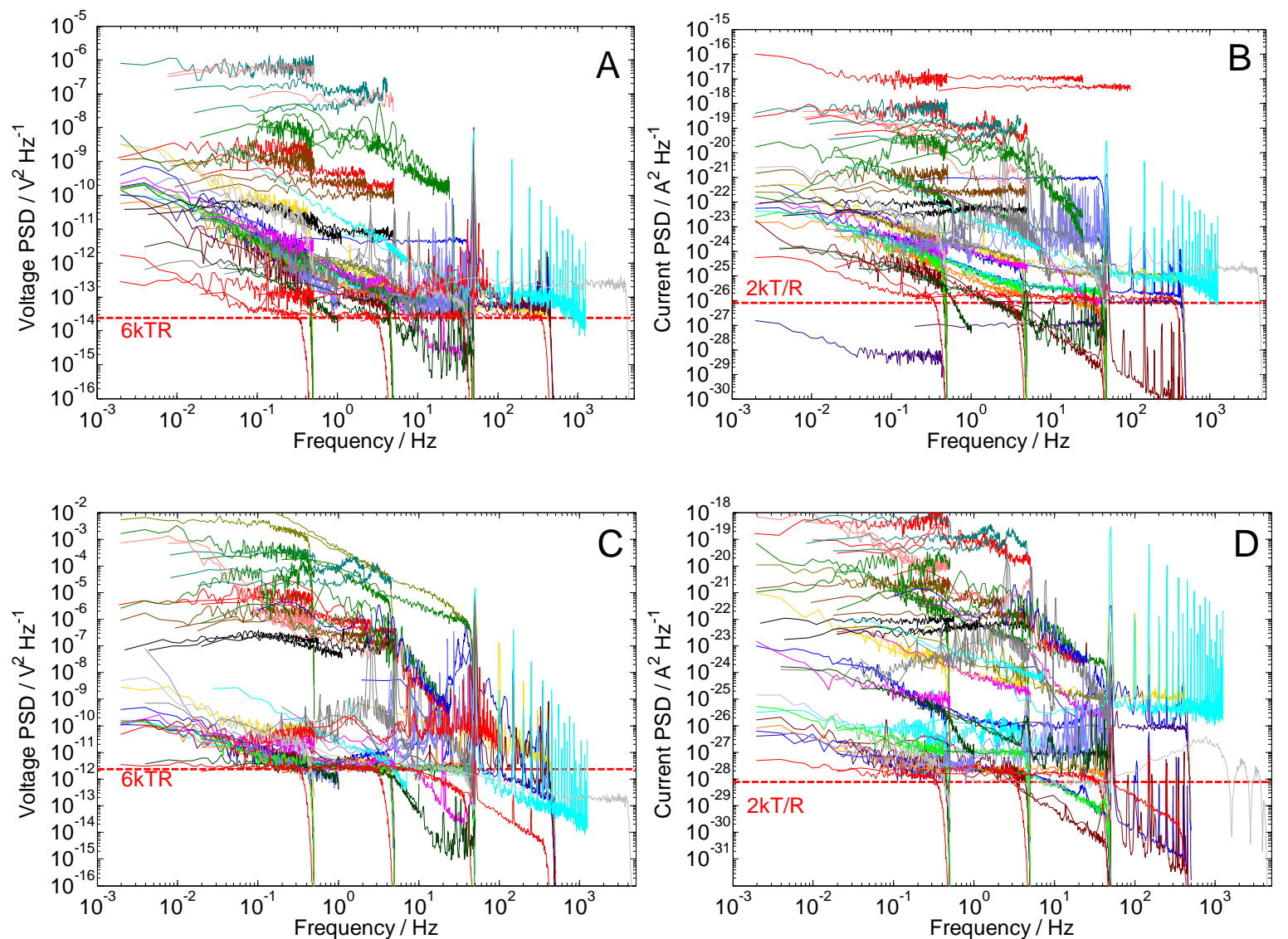

FIGURE 4. PSDs of potential $(A, C)$ and current $(B, D)$ fluctuations measured on dummy cells of $1 \mathrm{M} \Omega(\mathrm{A}, \mathrm{B})$ and $100 \mathrm{M} \Omega(C, \mathrm{D})(\mathrm{RR}-2017)$. 


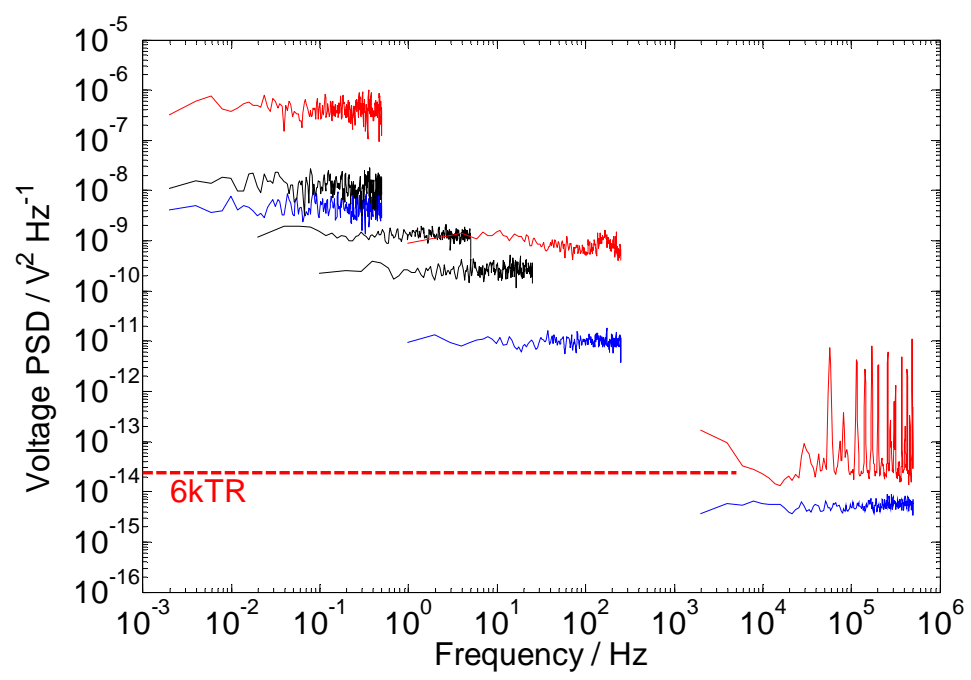

FIGURE 5. PSDs of potential fluctuations measured on dummy cells of $1 \mathrm{M} \Omega$ with three commercial equipments $O$ (black), P (blue), S (red) in RR-2014. 

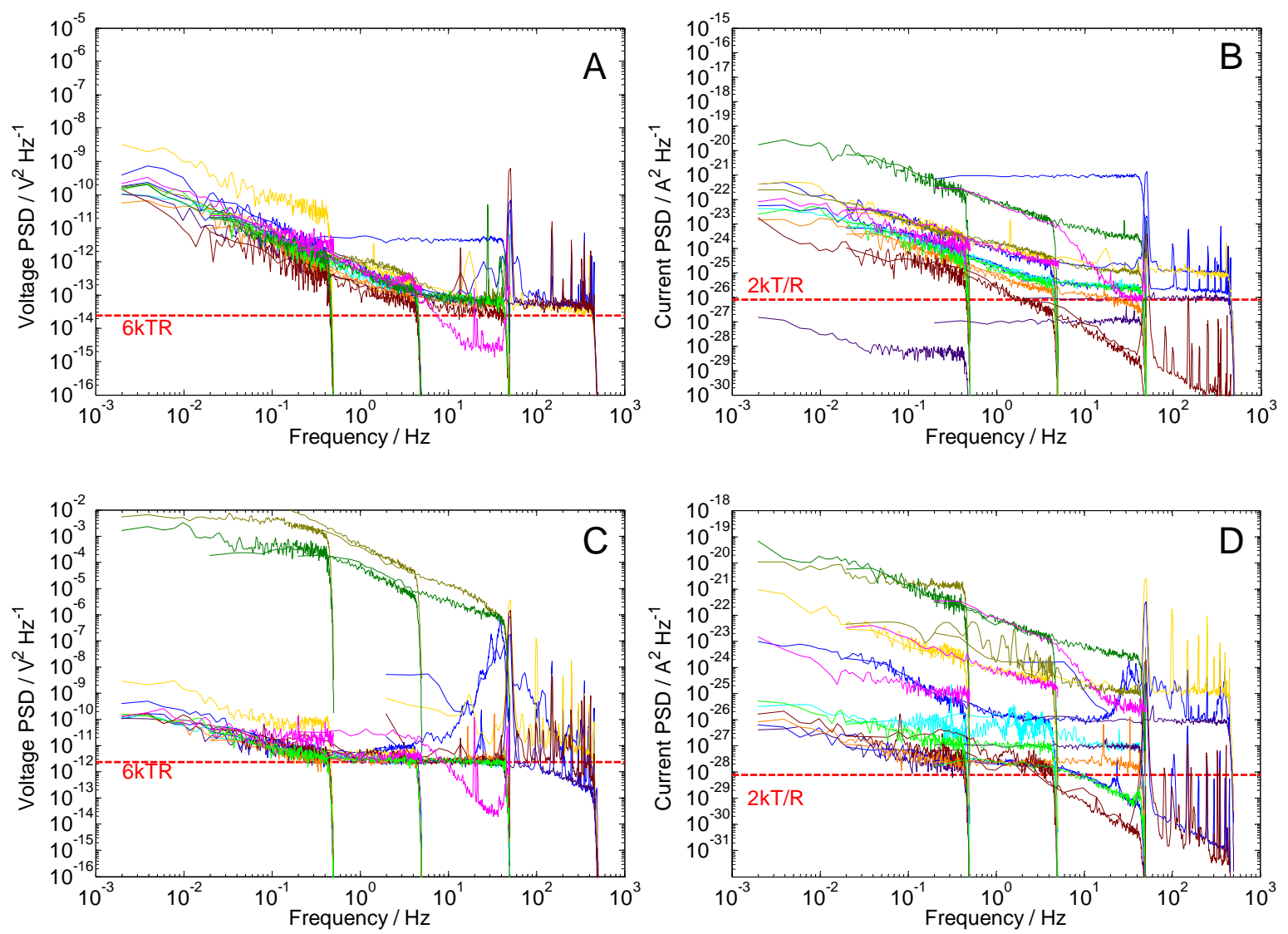

FIGURE 6. PSDs of potential $(A, C)$ and current $(B, D)$ fluctuations measured on dummy cells of $1 M \Omega(A, B)$ and $100 M \Omega(C, D)$ with instrument $G(R R-2017)$. 


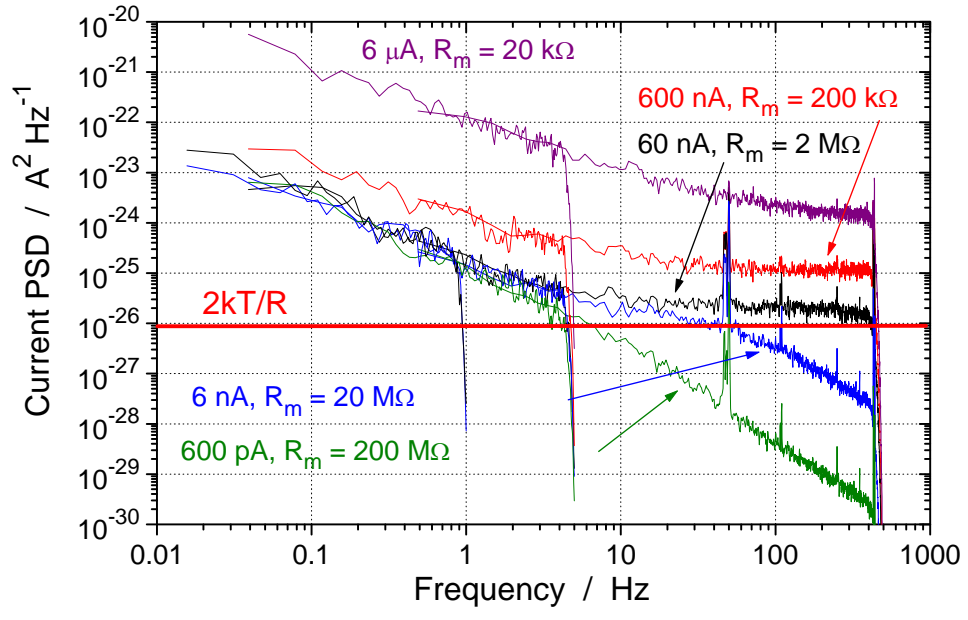

FIGURE 7. PSDs of current fluctuations measured on a dummy cell of $1 \mathrm{M} \Omega$ with equipment $G$ as a function of the I/E range used. 

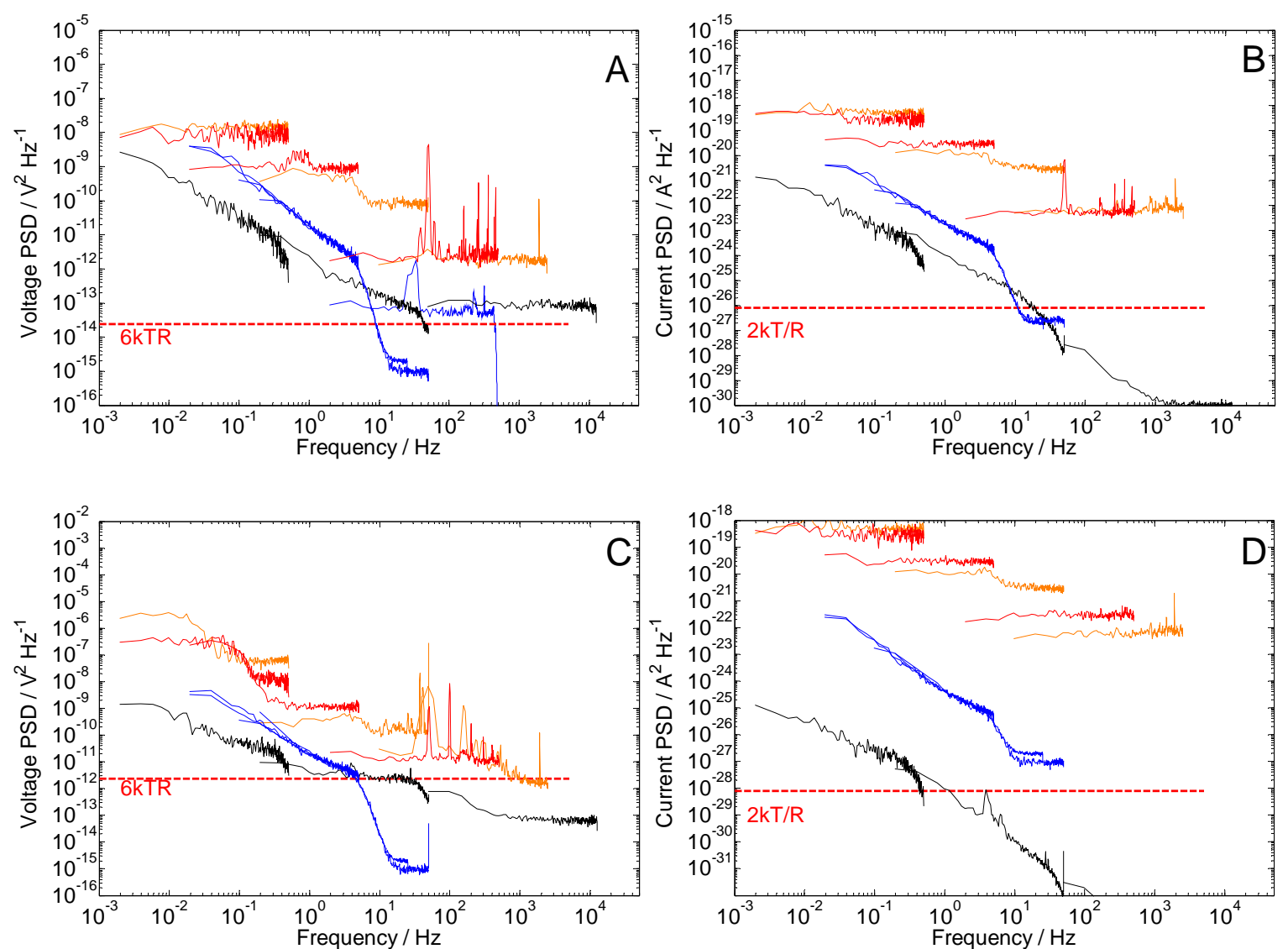

FIGURE 8. PSDs of potential $(A, C)$ and current $(B, D)$ fluctuations measured on dummy cells of $1 M \Omega(A, B)$ and $100 M \Omega(C, D)$ with equipment $B(R R-2016)$. 

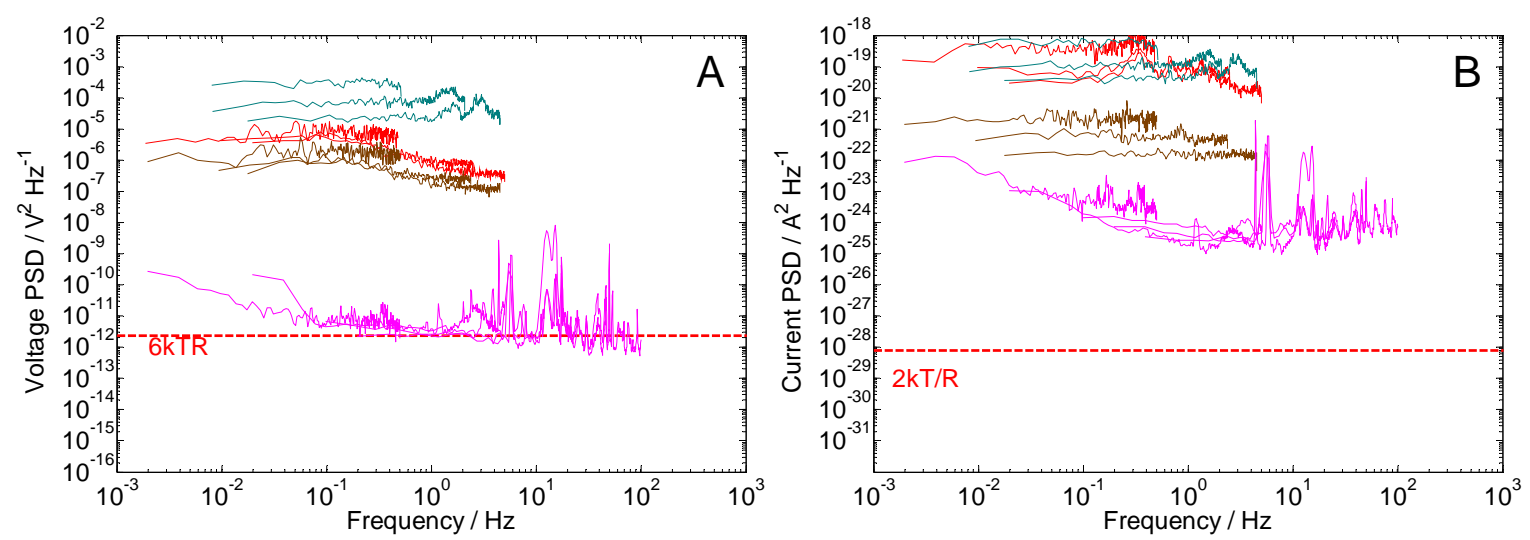

FIGURE 9. PSDs of potential (A) and current (B) fluctuations measured on dummy cells of $100 \mathrm{M} \Omega$ with commercial equipment S (RR-2016 and RR-2017). 